\title{
Multiple magnetic dipolarizations observed by THEMIS during a substorm
}

\author{
S. P. Duan ${ }^{1}$, Z. X. Liu ${ }^{1}$, J. Liang ${ }^{2}$, Y. C. Zhang ${ }^{1}$, and T. Chen ${ }^{1}$ \\ ${ }^{1}$ State Key Laboratory of Space Weather (Center for Space Science and Applied Research, Chinese Academy of Sciences), \\ Beijing, 100190, China \\ ${ }^{2}$ Department of Physics and Astronomy, University of Calgary, Calgary, Alberta, Canada
}

Received: 26 August 2010 - Revised: 27 December 2010 - Accepted: 11 January 2011 - Published: 15 February 2011

\begin{abstract}
The magnetic field dipolarization in the vicinity of substorm onset and during substorm expansion phase during the period of 06:00-06:40 UT on 15 February 2008 is investigated with observations from multiple probes of THEMIS. It is found that the magnetic dipolarization at the substorm onset (the onset time was about 06:14 UT) was not accompanied by obvious magnetic disturbance and ion bulk speed variation. The magnetic dipolarizations taking place during the substorm expansion phase observed by P4 ( $(-10.97,2.04,-3.03) R_{\mathrm{E}}$ and P3 $\sim(-11.32,1.15$, -3.10) $R_{\mathrm{E}}$ were mostly accompanied by high speed earthward ion bulk flow, but the magnetic dipolarizations occurring during the substorm expansion phase observed by P5 $\sim(-9.45,1.07,-2.85) R_{\mathrm{E}}$ were not accompanied by high speed earthward ion bulk flow. Before substorm onset THEMIS P3, P4, P5 all observed the $B_{\mathrm{x}}$ component fluctuation with a period of about $300 \mathrm{~s}$. After substorm onset earthward high speed ion bulk flow and significant magnetic disturbances both occurred at $\mathrm{P} 3$ and $\mathrm{P} 4$ locations. These results indicate that there is no one-to-one relationship between the near-Earth magnetic dipolarization and the earthward ion bulk flow. In particular, the magnetic dipolarization occurring on the earthward side of the inner near-Earth plasma sheet is not accompanied by high speed earthward ion bulk flow. The dipolarization at substorm onset is a local and small scale phenomenon. There are multiple magnetic dipolarizations occurring during the substorm expansion phase. The dipolarization process is very complex and is not simply an MHD process. It is accompanied by some kinds of plasma instabilities, the plasma sheet azimuthal expansion not only by earthward ion bulk flow during substorm. A sharp increase of the AE index does not always give an accurate substorm onset time for substorm analysis.
\end{abstract}

Correspondence to: S. P. Duan

(spduan@cssar.ac.cn)
Keywords. Magnetospheric physics (Magnetotail; Plasma sheet; Storms and substorms)

\section{Introduction}

The magnetic field dipolarization is a very key element in the substorm onset trigger process and usually accompanied with the plasma instabilities and waves. The dipolarization is associated with the current wedge formation, the crosstail current reduction, dispersionless energetic particles injection at night side near geosynchronous orbit, and the auroral breakup. The magnetic field dipolarization occurs at the same time as substorm onset time at the inner edge of the current sheet in the near-Earth tail (Liou et al., 2002; Rostoker, 2002; Miyashita et al., 2000). The dipolarization is defined as the $B_{\mathrm{Z}}$ component increase or the magnetic elevation angle increase (Lui et al., 1999; Baumjohann et al., 1999; Liou et al., 2002). The magnetic elevation angle is defined as $\theta=\tan ^{-1}\left(B_{\mathrm{z}} /\left(B_{\mathrm{x}}^{2}+B_{\mathrm{y}}^{2}\right)^{1 / 2}\right)$. The mechanism of the magnetic field dipolarization is not resolved and it is still an open question. Some researchers (e.g., Birn and Hesse, 1996; Shiokawa et al., 1997; Birn et al., 1999; Nakamura et al., 2009) proposed that the dipolarization was correlative with the high-speed earthward bulk flows, but Lui et al. (2008) pointed out that the dipolarization did not have a one-to-one relationship with the bursty bulk flow. The magnetic dipolarization onset at the midnight geosynchronous altitude was related to some plasma instabilities and prior to the auroral breakup. Lui et al. (1999) proposed that the near-Earth dipolarization was a non-MHD process and in a short interval there were three dipolarizations near substorm onset. Huang et al. (1992) pointed out that the energetic particles were heated and accelerated in the dipolarization processes in the near-Earth plasma sheet. The low frequency waves appeared near the dipolarization onset (Bauer et al., 1995a, b; Liang et al., 2009; Saito et al., 2010). Fairfield et al. (1998)

Published by Copernicus Publications on behalf of the European Geosciences Union. 


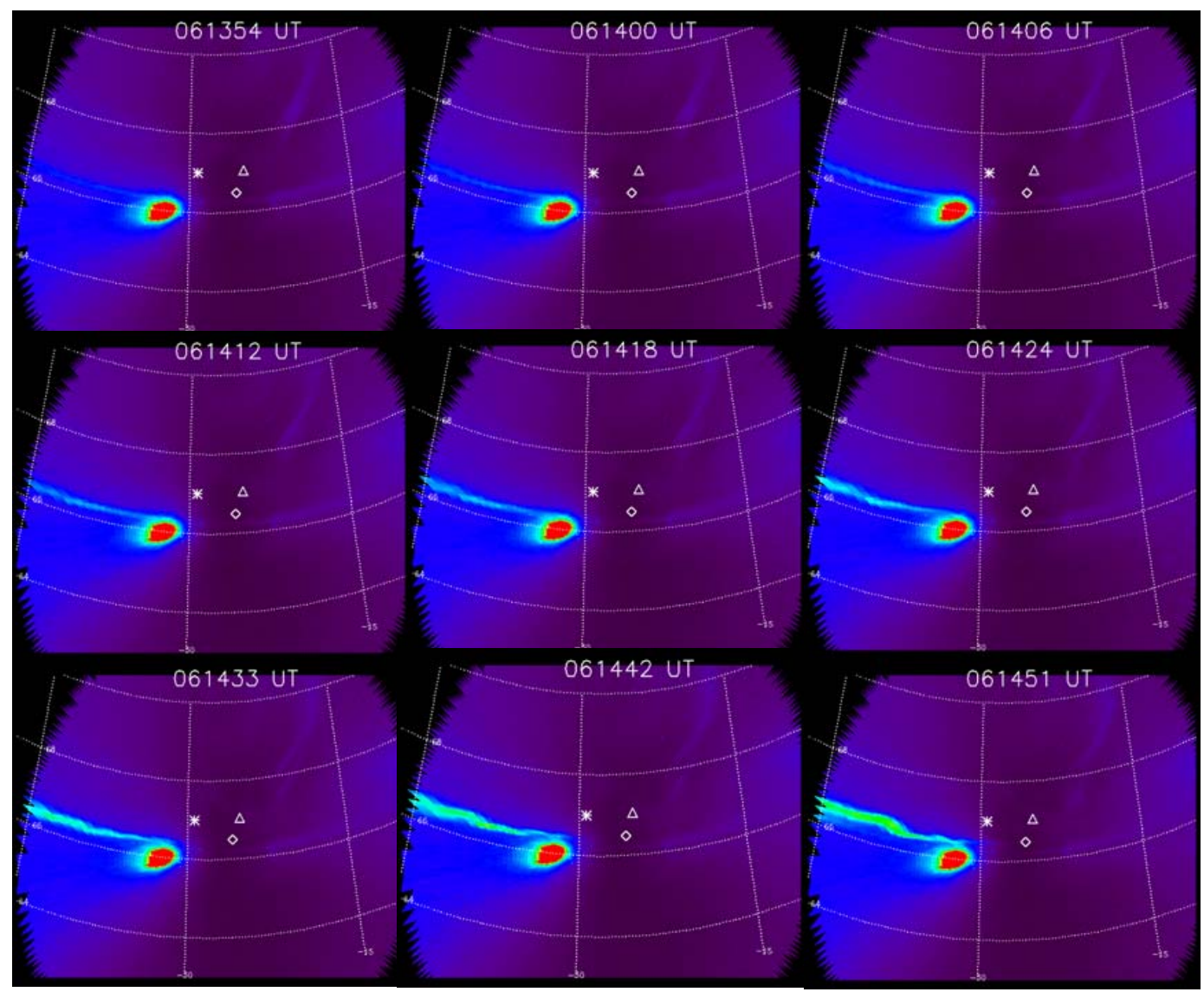

Fig. 1. The auroral images from THEMIS ground GILL ASI observation during 06:13:54-06:14:51 UT on 15 February 2008. The probes' footprints (THA: diamond; THD: triangle; THE: asterisk) are added in each auroral image.

pointed out that the continuously magnetic dipolarizations were associated with the plasma sheet expansions. On the basis of the previous research work on the magnetic dipolarization, the $B_{\mathrm{Z}}$ and $B_{\mathrm{x}}$ components had the most attention, but the $B_{\mathrm{y}}$ component is seldom discussed. In this article, the $B_{\mathrm{y}}$ component contribution to the magnetic dipolarization was considered. The triggering mechanism of magnetic dipolarization is still an open question. The previous multiple dipolarizations near substorm onset were mostly observed by a single satellite. Simultaneous observations from multiple probes of THEMIS give us a good opportunity to distinguish the temporal and spatial variations.

The main purpose of this article is to use observations from multiple probes of THEMIS to investigate the magnetic dipolarization feature in the vicinity of substorm onset and during substorm expansion phase and to show some evidences for the relationship between the magnetic dipolarization and bursty bulk flow. The dipolarization occurring during substorm expansion phase was mostly accompanied by the bursty bulk flow and was observed far away from the Earth in the magnetotail plasma sheet, while the magnetic dipolarization taking place on the earthward side of the in- ner near-Earth plasma sheet was not usually accompanied by high speed earthward ion bulk flow.

\section{Observations}

The THEMIS mission provides good opportunities to investigate the magnetospheric substorm (Angelopoulos, 2008). From December 2007 to April 2008, the THEMIS satellites are in the tail science phase the apogee of the orbits are in the magnetotail. The 06:14 UT substorm on 15 February 2008 was chosen to investigate multiple magnetic dipolarizations during a substorm.

\subsection{Identification of substorm onset time}

\subsubsection{Auroral break up}

From THEMIS ground auroral observation, high resolution auroral images data can be obtained. Figure 1 shows the evolution of auroral brightening during 06:13:54 to 06:14:51 UT on 15 February 2008. The probes' footprints - THA marked by diamond, THD marked by triangle, THE marked by 


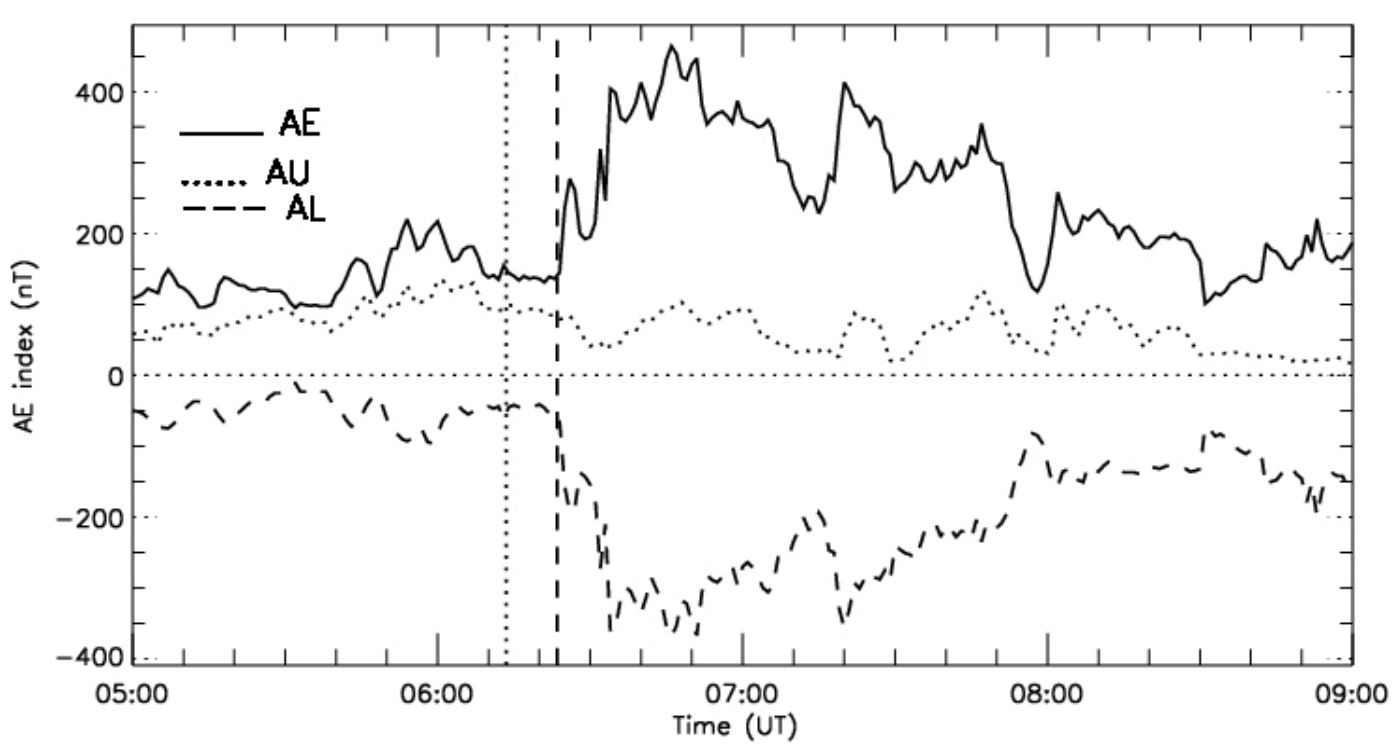

Fig. 2. The AE index in the intervals 05:00-09:00 UT on 15 February 2008, the vertical dotted line is marked substorm onset time, 06:14 UT.

asterisk - have been added in each auroral image. Aurora brightened suddenly at 06:14 UT. Then aurora expanded in the east-west direction and to the polarward side. On the basis of these aurora evolution, we can identify the substorm onset time is at about 06:14 UT.

\subsubsection{AE index}

Figure 2 shows the $\mathrm{AE}, \mathrm{AL}$ and $\mathrm{AU}$ indices variation during the intervals of 05:00-09:00 UT on 15 February 2008. The vertical dotted line was marked substorm onset time, about 06:14 UT. At this time the AE and AL index had no obvious variation. But at about 06:24 UT the AE and AL indices changed sharply, which was marked by the vertical dashed line in Fig. 2.

\subsection{Multiple magnetic dipolarizations observed by THEMIS}

The FGM, SST and ESA data from THEMIS were adopted in this event analysis. A substorm occurred at about 06:14 UT on 15 February 2008 and was observed by THEMIS P5, P4 and P3 in the near-Earth plasma sheet. In the following sections, the magnetic dipolarization features are described in detail. The simultaneous observations of plasma parameters and the magnetic field from P5, P4 and P3 probes at different locations are presented in Fig. $3 \mathrm{a}, \mathrm{b}$ and $\mathrm{c}$, respectively. The formats of these three figures are the same, from top to bottom, the plots are hot ion density, $N$, (black line) and ion temperature, $T$ (red line $0.1 T_{\text {ion }}$ ), the plasma beta, $\beta$, i.e., the ratio of the plasma thermal pressure to the magnetic field pressure, three perpendicular components of ion bulk flow in the GSM coordinate, $v_{\text {perpx }}$ (blue line), $v_{\text {perpy }}$ (green line) and $v_{\text {perpz }}$ (red line), the magnetic field $B_{\mathrm{x}}$ com- ponent, the $B_{\mathrm{Z}}$ component, the total of the magnetic field $B_{\mathrm{t}}$ (black line) and the $B_{\mathrm{y}}$ component (green line), the magnetic field elevation angle, $\theta=\tan ^{-1}\left(B_{\mathrm{z}} /\left(B_{\mathrm{x}}^{2}+B_{\mathrm{y}}^{2}\right)^{1 / 2}\right)$, and the angle between the magnetic field $\boldsymbol{B}$ and ion bulk flow $\boldsymbol{v}, \theta_{\mathrm{Bv}}$, respectively. The red vertical dotted lines in these figures mark the substorm onset time. The black vertical dotted lines mark the magnetic dipolarizations occurring during the substorm expansion phase. During the period of 06:00 UT to 06:40 UT, these three probes observed the magnetic field and plasma parameters variations at different locations in the near-Earth plasma sheet. This constellation is very useful for distinguishing the spatial and temporal phenomena. In this interval, THD (P3) was the far from the Earth, $X \sim-11.30 R_{\mathrm{E}}$ and THA (P5) was the nearest from the Earth, $X \sim-9.45 R_{\mathrm{E}}$. THE (P4) was between THA and THD, $X \sim-11.00 R_{\mathrm{E}}$. From THA (P5) location, we found that P5 was at its apogee during this period, 06:00-06:40 UT, and so it moved very slowly. That was helpful to investigate the substorm temporal evolutions.

Before substorm onset at THA, $X \sim-9.45 R_{\mathrm{E}}$, ion number density was about $0.5 \mathrm{~cm}^{-3}$, temperature was about $4.5 \mathrm{keV}$, the plasma $\beta$ was larger than 4 , ion bulk earthward flow speed was mostly small, the $v_{\text {perpx }}$ component approached zero, the $B_{\mathrm{x}}$ component decreased continually, the minima value was about $-13 \mathrm{nT}$, the $B_{\mathrm{z}}$ component was very small and about $2.5 \mathrm{nT}$, the total magnetic field $B_{\mathrm{t}}$ was about $13 \mathrm{nT}$, and the magnetic field elevation angle was about 15 degrees. The plasma $\beta$ was about 4 in the interval of 06:05 UT to 06:13 UT. These values indicate that THA located near the earthward side of the inner near-Earth plasma sheet or in the central plasma sheet. THA observed the decrease of $B_{\mathrm{X}}$ absolute value from $10 \mathrm{nT}$ to $5 \mathrm{nT}$ and no clear increase of $B_{\mathrm{y}}$ and $B_{\mathrm{z}}$ components, but the elevation 


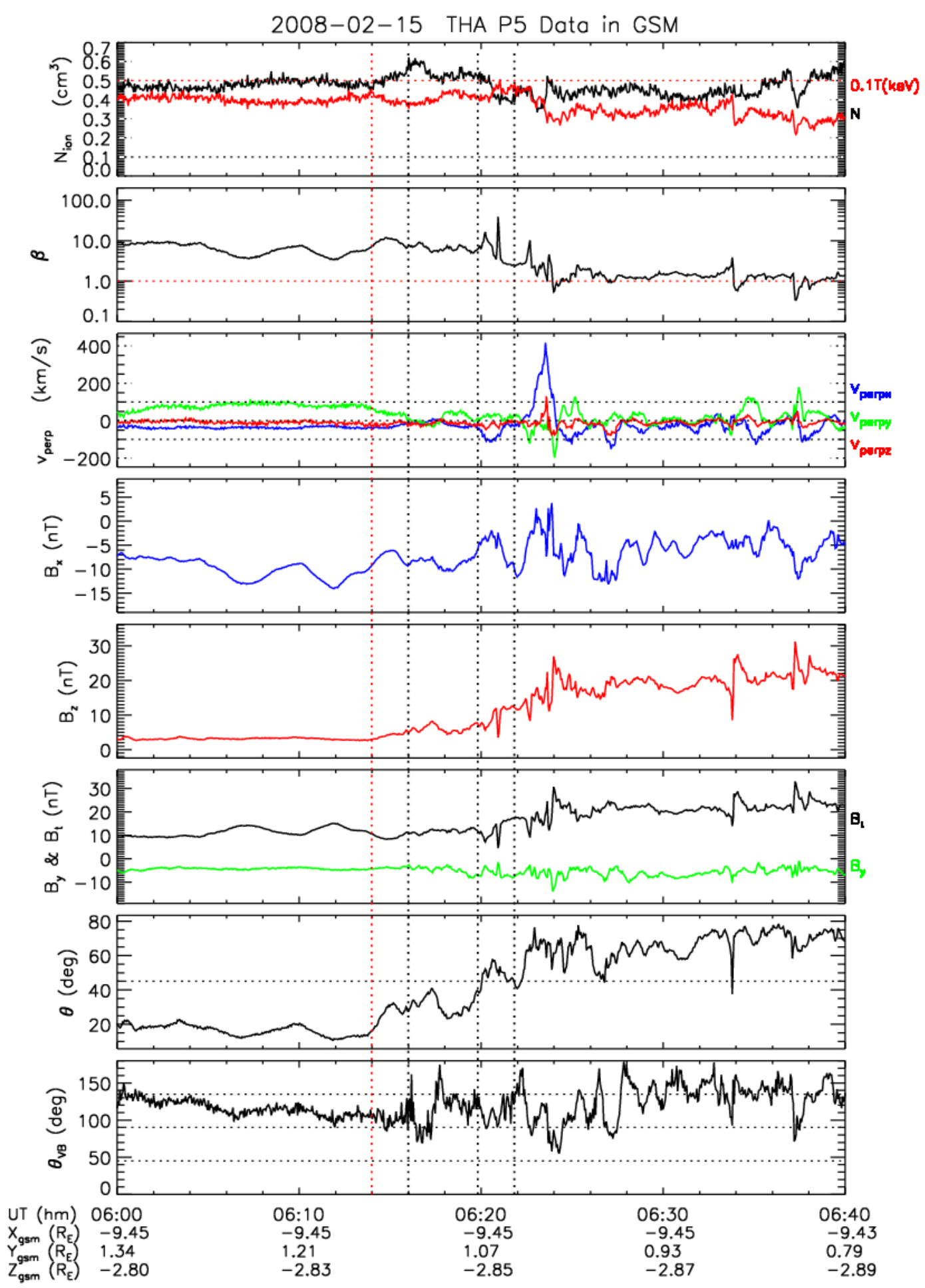

Fig. 3. THEMIS multiple probes observed the substorm occurred at 06:14 UT on 15 February 2008 in the near-Earth plasma sheet. Panels (a), (b) and (c) are from THA, THE and THD, respectively. The format of these three figures are the same, from top to bottom are hot ion density, $N$, (black line) and temperature $T$ (red line $0.1 T_{\text {ion }}$ ), the plasma beta, $\beta$, three perpendicular components of ion bulk flow $v_{\text {perpx }}$ (blue line), $v_{\text {perpy }}\left(\right.$ green line) and $v_{\text {perpz }}$ (red line), $B_{\mathrm{x}}, B_{\mathrm{z}}, B_{\mathrm{t}}$ (black line) and $B_{\mathrm{y}}\left(\right.$ green line), the magnetic elevation angle $\theta=\tan ^{-1}\left(B_{\mathrm{Z}} /\left(B_{\mathrm{x}}^{2}+B_{\mathrm{y}}^{2}\right)^{1 / 2}\right)$, the angle between the magnetic field and the ion bulk flow $\theta_{\mathrm{Bv}}$. 


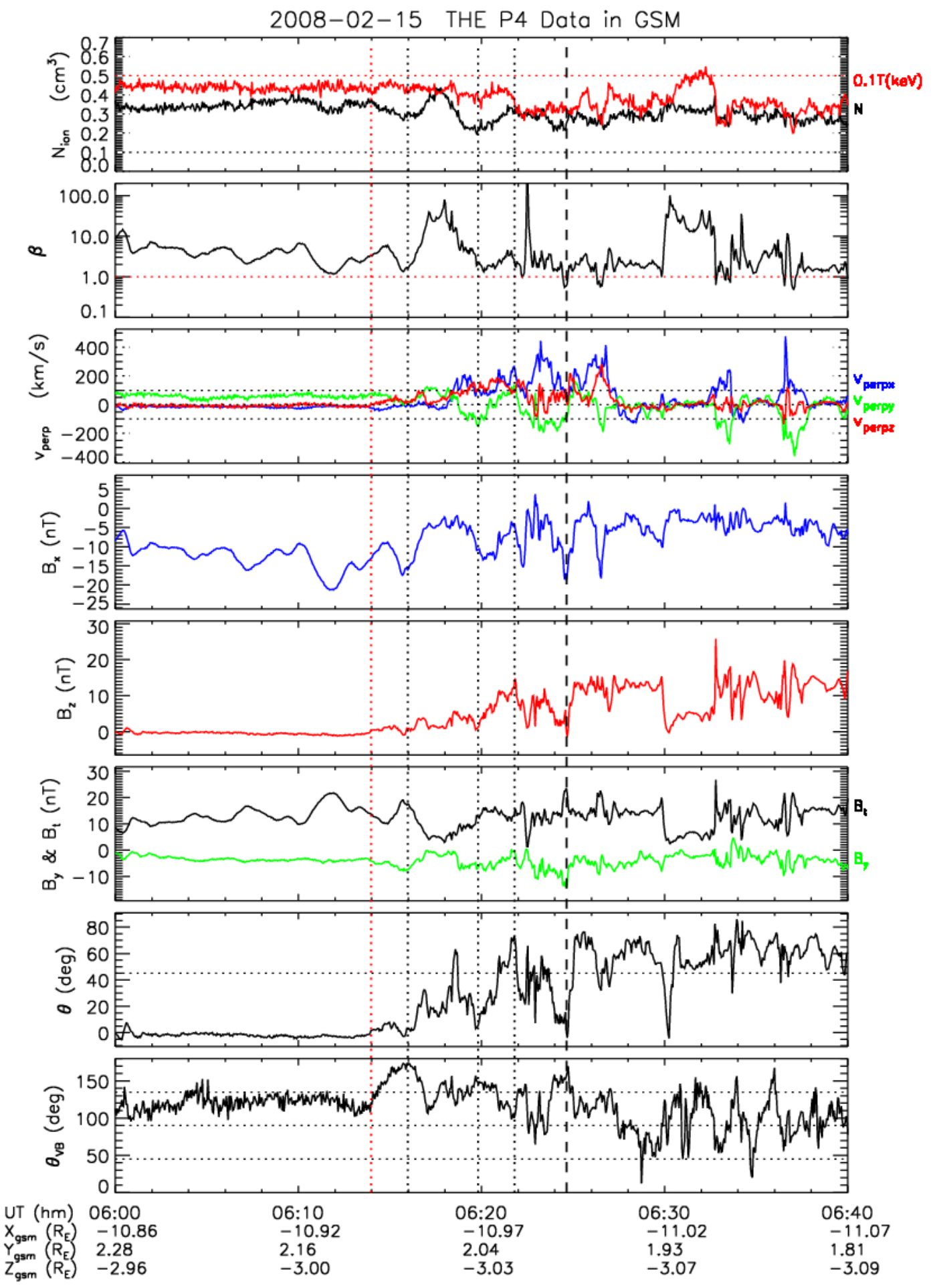

Fig. 3. Continued.

angle increased obviously from 15 degrees to 30 degrees at about 06:14 UT, marked by the red vertical dotted line in Fig. 3a. Before substorm onset at THE, ion number density was about $0.3 \mathrm{~cm}^{-3}$, temperature was about $5 \mathrm{keV}$, the plasma $\beta$ was lager than 1 , ion bulk flow speed was mostly small, and approached zero, the $B_{\mathrm{X}}$ component decreased continually, the minima value was about $-20 \mathrm{nT}$, the $B_{\mathrm{z}}$ component was very small and about zero, the total magnetic 


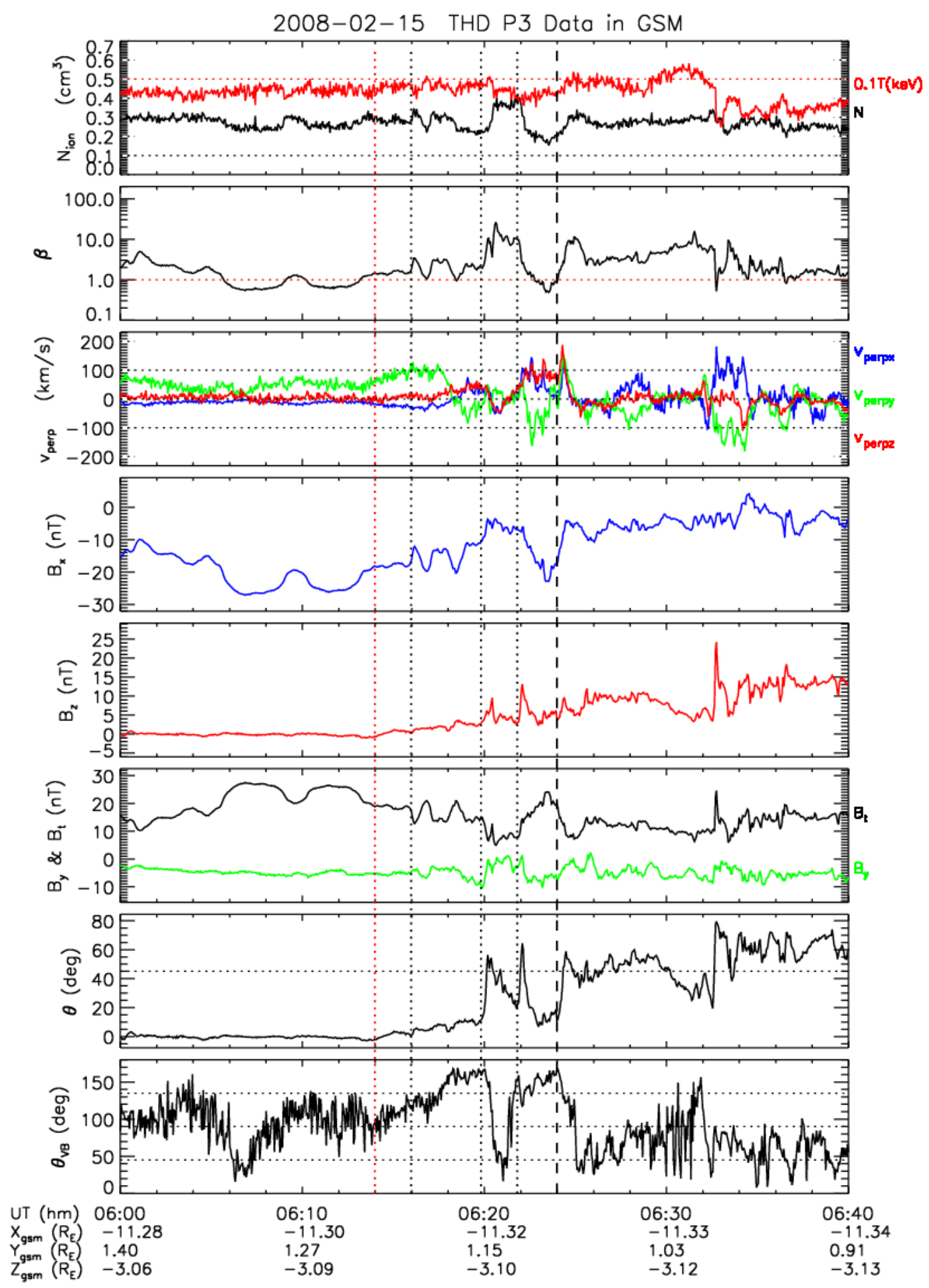

Fig. 3. Continued.

field maximum $B_{\mathrm{t}}$ was about $20 \mathrm{nT}$, and the magnetic field elevation angle was about zero degrees. The plasma $\beta$ was large than 1 in the interval of 06:05 UT to 06:13 UT, indicating that THE located in the central plasma sheet. But near substorm onset, the $B_{\mathrm{x}}$ component absolute values decreased significantly from $15 \mathrm{nT}$ to $10 \mathrm{nT}$ and the $B_{\mathrm{Z}}$ component increased slightly. The elevation angle increased from about 0 degree to about 10 degree at about 06:14 UT, marked by 
the red vertical dotted line in Fig. 3b. Observations from THD were mostly similar to the observations of THE in the interval of 06:05 UT to 06:13 UT. Before substorm onset at THD, ion number density was about $0.3 \mathrm{~cm}^{-3}$, temperature was about $5 \mathrm{keV}$, the plasma $\beta$ was about 0.7 , ion bulk flow speed was mostly small, and the $v_{\text {perpx }}$ component approached zero, the $B_{\mathrm{x}}$ component decreased continually, the minima value was about $-27 \mathrm{nT}$, the $B_{\mathrm{z}}$ component was very small and about zero, the total magnetic field maximum $B_{\mathrm{t}}$ was about $27 \mathrm{nT}$, equal to the absolute value of the $B_{\mathrm{x}}$ component. The magnetic field elevation angle was about zero degrees. The plasma $\beta$ was less than 1 in the interval of 06:05 UT to 06:13 UT. These values indicated that THD located in the outer plasma sheet or plasma sheet boundary layer (PSBL). At about substorm onset time, the $B_{\mathrm{x}}, B_{\mathrm{y}}$ and $B_{\mathrm{z}}$ components all changed little. The elevation angle increased very weakly.

At 06:16 UT, at THE the $B_{\mathrm{x}}$ magnitude decreased suddenly from $15 \mathrm{nT}$ to $0 \mathrm{nT}$. The $B_{\mathrm{z}}$ component increased slightly and the magnetic elevation angle increased from about 0 degree to 30 degree. At the same time, 06:16 UT, THA observed the $B_{\mathrm{Z}}$ component slightly increased from about $5 \mathrm{nT}$ to $8 \mathrm{nT}$ and the magnetic elevation angle increased from about 30 degrees to 40 degrees. At 06:16 UT, THD observed a very slight increase of the magnetic elevation angle from about 0 degree to 5 degrees. During this dipolarization process, the $\mathrm{x}$-component of the perpendicular earthward ion bulk flow, $v_{\text {perpx }}$, observed by THA, THE and THD approached to zero. The time of these variations is marked by the first black vertical dotted lines in Fig. 3 .

At 06:19:50 UT, these three probes (THD, THE and THA) all observed the $B_{\mathrm{Z}}$ component and the magnetic field elevation angle increased significantly. THD observed the decrease in the absolute values of the $B_{\mathrm{x}}$ and $B_{\mathrm{y}}$ components from $10 \mathrm{nT}$ to about $0 \mathrm{nT}$ and the increase in the $B_{\mathrm{z}}$ component from $2 \mathrm{nT}$ to $10 \mathrm{nT}$. The elevation angle increased from 10 degrees to 60 degrees. THE observed the $B_{\mathrm{x}}$ and $B_{\mathrm{y}}$ components changed little at this time, but the $B_{\mathrm{Z}}$ component increase obviously from $1 \mathrm{nT}$ to about $15 \mathrm{nT}$. The elevation angle increased from 5 degrees to 75 degrees. THA observed the $B_{\mathrm{x}}$ and $B_{\mathrm{y}}$ magnitudes showing small decrease, but the $B_{\mathrm{z}}$ component increased from $5 \mathrm{nT}$ to about $12 \mathrm{nT}$. The elevation angle increased from 30 degrees to 65 degrees. At this magnetic dipolarization, THE observed the dipolarization accompanied by the earthward ion bulk flow with the $v_{\text {perpx }}$ component approaching $100 \mathrm{~km} \mathrm{~s}^{-1}$, but THA and THD both did not observe high speed earthward ion bulk flow. The time of these variations is marked by the second black vertical dotted lines in Fig. 3.

At about 06:21:50 UT, marked by the third black vertical dotted lines in Fig. 3, THD observed sudden increase of the $B_{\mathrm{Z}}$ component from $3 \mathrm{nT}$ to $15 \mathrm{nT}$ and sudden increase of the elevation angle from 20 degrees to about 70 degrees. At about this time, 06:21:50 UT, at THA, the $B_{\mathrm{x}}$ magnitude decreased and the elevation angle increased sharply from 40 de- grees to 70 degrees. The magnetic elevation angle was larger than 45 degrees for a long time during substorm expansion phase. However, THE observed a slight magnetic dipolarization with the magnetic elevation angle increase from about 50 degrees to 60 degrees at 06:21:50 UT.

At about 06:24 UT, marked by the vertical dashed line in Fig. 3b and c, THD observed the clear magnetic dipolarization with the elevation angle increase from about 15 degrees to 60 degrees and high-speed earthward ion bulk flow with the $v_{\text {perpx }}$ about $100 \mathrm{~km} \mathrm{~s}^{-1}$. After this time, the elevation angle remained having a large value of about 45 degrees in the 6 min interval. THE observed the same significant magnetic dipolarization and high speed earthward ion bulk flow with the $v_{\text {perpx }}$ about $200 \mathrm{~km} \mathrm{~s}^{-1}$ at about 06:24:40 UT. From Fig. 2, the AE index sharply increased at 06:24 UT, which was marked by the vertical dashed line. The sudden increase of AE index occurred during the substorm expansion phase but not at the substorm onset.

\section{Discussion and conclusions}

From the observations of multiple probes of THEMIS during this substorm process, multiple magnetic dipolarizations occurred during the substorm expansion phase. These dipolarizations have different characteristics. At the substorm onset time about 06:14 UT, an intense dipolarization was observed by the nearest probe, THA, at about $X \sim-9.45 R_{\mathrm{E}}$ in the central plasma sheet. During this dipolarization, THA did not observe high speed earthward ion bulk flow. At about this time, 06:14 UT, a weak dipolarization was observed by THE at about $X \sim-10.94 R_{\mathrm{E}}$ in the plasma sheet and by THD at about $X \sim-11.31 R_{\mathrm{E}}$ in the outer plasma sheet. THD and THE did not observe significant dipolarization at this time at different locations. At about 06:14 UT, MLT of THA, THD and THE were $23.56 \mathrm{~h}, 23.60 \mathrm{~h}$ and $23.29 \mathrm{~h}$, respectively. The distance between THA and THE in the X direction was $\Delta X \sim 1.49 R_{\mathrm{E}}$. The difference MLT value between THA and THE was about $0.27 \mathrm{~h}$. These location parameters indicate that THA, THD and THE located in a small spatial range. The different observations from these three probes indicate that the magnetic dipolarization at substorm onset time is a local and small spatial scale process. After substorm onset THE observed the earthward ion bulk flow speed increase. During the substorm expansion phase these three THEMIS probes observed multiple magnetic dipolarizations at the different locations at the same time 06:16 UT, 06:19:50 UT, 06:21:50 UT. During these three dipolarizations, THA, the nearest probe, did not observe high speed earthward ion bulk flow in the plasma sheet, but THE, the middle probe among these three probes, observed the earthward ion bulk flow speed larger than $100 \mathrm{~km} \mathrm{~s}^{-1}$ during the 06:19:50 UT and 06:21:50 UT dipolarization period. THD, the furthest probe, observed no high speed earthward ion bulk flow in the 06:16 UT and 06:19:50 UT dipolarizations, but observed 
high speed earthward ion bulk flow in the 06:21:50 UT dipolarization. The x-component of the perpendicular ion bulk flow, $v_{\text {perpx }}$, observed by THA, THE and THD was near zero during the 06:16 UT dipolarization. Dipolarization after substorm onset is maybe correlative with the azimuthal expansion of the plasma sheet. Dipolarization during the later substorm expansion phase has relationship with high speed earthward ion bulk flow. These different dipolarization phenomena during substorm expansion phase imply that there is no one-to-one relationship between the near-Earth magnetic dipolarization and the high speed earthward ion bulk flow. This observation result is consistent with the result of Lui et al. (2008). It suggests that the near-Earth dipolarization is a complex process, not a simple MHD process. These observations mean that the magnetic dipolarization is not all caused by the ion bulk flow, especially near the earthward of the inner near-Earth plasma sheet.

Another interesting phenomenon during this substorm is that there is no obvious magnetic disturbance in the vicinity of substorm onset. On the basis of the $B_{\mathrm{x}}$ component fluctuation, there was a low frequency wave with a period of about $300 \mathrm{~s}$ before substorm onset observed by THA, THE and THD at the different locations in the plasma sheet. After substorm onset, i.e., during the substorm expansion phase, the magnetic disturbances became very intense and the period of the magnetic fluctuations became shorter than the period of the low frequency wave before substorm onset. This observational result of low frequency waves in the vicinity of substorm onset is consistent with the observational result of the previous research work (e.g., Liang et al., 2009; Bauer et al., 1995).

The sudden increase of the AE index is usually used as the substorm onset signature by many researchers (e.g., Hsu and McPherron, 2003; Huang, 2005). From this study on substorm, we found that the time of sharp increase of AE index was within the substorm expansion phase, not at the substorm onset time. Before the sudden increases of the $\mathrm{AE}$ index, both the near-Earth magnetic dipolarization and auroral brightening have already occurred. So we should be alert when we only use the AE index to identify substorm onset time.

According to the above observations of multiple magnetic dipolarizations during the substorm, the conclusions can be drawn as follow. There are multiple magnetic dipolarizations occurring during a substorm in the near-Earth plasma sheet. These dipolarizations observed by multiple probes of THEMIS have different mechanisms and properties. The property of the dipolarization at substorm onset is different with the one of the dipolarizations during substorm expansion phase. The dipolarization at the earthward side of the near-Earth plasma sheet has no relationship with high speed earthward ion bulk flow. It may be driving by some kinds of plasma instabilities. But the dipolarization far way from the earth in the near-Earth plasma sheet usually has a relationship with high speed earthward ion bulk flow. Dipolarization at substorm onset is a local and small scale phenomenon, while dipolarizations during substorm expansion phase have larger spatial scale and are correlative with the azimuthal expansion of plasma sheet or high speed earthward ion bulk flow. The dipolarization process is very complex and is not simply an MHD process. It is accompanied by many kinds of other phenomena not only by earthward ion bulk flow during substorm. A sharp increase in the AE index does not always give an accurate substorm onset time for substorm analysis.

Acknowledgements. We acknowledge NASA contract NAS502099 and V. Angelopoulos for use of data from the THEMIS Mission. Specifically: "D. Larson and R. P. Lin for use of SST data, C. W. Carlson and J. P. McFadden for use of ESA data, K. H. Glassmeier, U. Auster and W. Baumjohann for the use of FGM data provided under the lead of the Technical University of Braunschweig and with financial support through the German Ministry for Economy and Technology and the German Centre for Aviation and Space (DLR) under contract 50 OC 0302, S. Mende and E. Donovan for use of the ASI data, and the CSA for logistical support in fielding and data retrieval from the GBO stations." We would like to offer special thanks to X. Y. Xing for her useful comments and generous help. The authors thank NASA CDAWeb and Taiwan AIDA for THEMIS data and Kyoto World Data Centre for providing the $\mathrm{AE}, \mathrm{AL}$ and AU indices. This work was supported by the National Natural Science Foundation of China under Grant No 40704027, 40974099, 40731054 and Specialized Research Fund for State Key Laboratories.

Topical Editor R. Nakamura thanks two anonymous referees for their help in evaluating this paper.

\section{References}

Angelopoulos, V.: The THEMIS Mission, Space Sci. Rev., 141, 534, 2008.

Bauer, T. M., Baumjohann, W., Treumann, R. A., Sckopke, N., and Lühr, H.: Low-Frequency Waves in the NearEarth Plasma Sheet, J. Geophys. Res., 100(A6), 9605-9617, doi:10.1029/95JA00136, 1995a.

Bauer, T. M., Baumjohann, W., and Treumann, R. A.: Neutral sheet oscillations at substorm onset, J. Geophys. Res., 100, 2373723742, 1995b.

Baumjohann, W., Hesse, M., Kokubun, S., Mukai, T., Nagai, T., and Petrukovich, A. A.: Substorm dipolarization and recovery, J. Geophys. Res., 104, 24995-25000, 1999.

Birn, J. and Hesse, M.: Details of current disruption and diversion in simulations of magnetotail dynamics, J. Geophys. Res., 101(A7), 15345-15358, 1996.

Birn, J., Hesse, M., Haerendel, G., Baumjohann, W., and Shiokawa, K.: Flow braking and the substorm current wedge, J. Geophys. Res., 104(A9), 19895-19903, 1999.

Fairfield, D. H., Mukai, T., Lui, A. T. Y., Cattell, C. A., Reeves, G. D., Nagai, T., Rostoker, G., Singer, H. J., Kaiser, M. L., Kokubun, S., Lazarus, A. J., Lepping, R. P., Nakamura, M., Steinberg, J. T., Tsuruda, K., Williams, D. J., and Yamamoto, T.: Geotail observations of substorm onset in the inner magnetotail, J. Geophys. Res., 103(A1), 103-117, 1998. 
Hsu, T.-S. and McPherron, R. L.: Occurrence frequencies of IMF triggered and nontriggered substorms, J. Geophys. Res., 108(A7), 1307, doi:10.1029/2002JA009442, 2003.

Huang, C.-S.: Variations of polar cap index in response to solar wind changes and magnetospheric substorms, J. Geophys. Res., 110, A01203, doi:10.1029/2004JA010616, 2005.

Huang, C. Y., Frank, L. A., Rostoker, G., Fennell, J., and Mitchell, D. G.: Nonadiabatic Heating of the Central Plasma Sheet at Substorm Onset, J. Geophys. Res., 97(A2), 1481-1495, 1992.

Liang, J., Liu, W. W., Donovan, E. F., and Spanswick, E.: In-situ observation of ULF wave activities associated with substorm expansion phase onset and current disruption, Ann. Geophys., 27, 2191-2204, doi:10.5194/angeo-27-2191-2009, 2009.

Liou, K., Meng, C.-I., Lui, A. T. Y., Newell, P. T., and Wing, S.: Magnetic dipolarization with substorm expansion onset, J. Geophys. Res., 107(A7), 1131, doi:10.1029/2001JA000179, 2002.

Lui, A. T. Y., Liou, K., Nosé, M., Ohtani, S., Williams, D. J., Mukai, T., Tsuruda, K., and Kokubun, S.: Near-Earth dipolarization: Evidence for a non-MHD process, Geophys. Res. Lett., 26(19), 2905-2908, doi:10.1029/1999GL003620, 1999.

Lui, A. T. Y., Angelopoulos, V., LeContel, O., Frey, H., Donovan, E., Sibeck, D. G., Liu, W., Auster, H. U., Larson, D., Li, X., Nosé, M., and Fillingim, M. O.: Determination of the substorm initiation region from a major conjunction interval of THEMIS satellites, J. Geophys. Res., 113, A00C04, doi:10.1029/2008JA013424, 2008.
Miyashita, Y., Machida, S., Mukai, T., Saito, Y., Tsuruda, K., Hayakawa, H., and Sutcliffe, P. R.: A statistical study of variations in the near and middistant magnetotail associated with substorm onsets: Geotail observations, J. Geophys. Res., 105, 15913-15930, 2000.

Nakamura, R., Retinò, A., Baumjohann, W., Volwerk, M., Erkaev, N., Klecker, B., Lucek, E. A., Dandouras, I., André, M., and Khotyaintsev, Y.: Evolution of dipolarization in the nearEarth current sheet induced by Earthward rapid flux transport, Ann. Geophys., 27, 1743-1754, doi:10.5194/angeo-27-17432009, 2009.

Rostoker, G.: Identification of substorm expansive phase onsets, J. Geophys. Res., 107(A7), 1137, doi:10.1029/2001JA003504, 2002.

Saito, M. H., Miyashita, Y., Fujimoto, M., Liou, K., Saito, Y., and Sigwarth, J. B.: Stepwise feature of aurora during substorm expansion compared with the near-Earth tail dipolarization: Possible types of substorm dynamics, J. Geophys. Res., 115, A02207, doi:10.1029/2009JA014572, 2010.

Shiokawa, K., Baumjohann, W., and Haerendel, G.: Braking of high speed flows in the near-Earth tail, Geophys. Res. Lett., 10, 1179, 1997. 